http://dx.doi.org/10.18675/1981-8106.vol26.n52.p212-231

\title{
A arte integrando gerações em um contexto educacional não escolar
}

\section{El arte integrando generaciones en un contexto educacional no escolar}

\section{The Art integrating generations in a non-school educational context}

Selma Machado Simão'

'Universidade Estadual Paulista - Câmpus de Rio Claro, São Paulo - Brasil. E-mail: selma.msimao@gmail.com

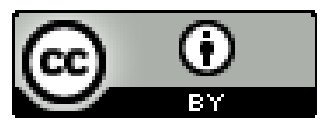

Educação: teoria e prática, Rio Claro, SP, Brasil - eISSN: 1981-8106

Está licenciada sob Licença Creative Common

\section{Resumo}

Este artigo versa sobre uma pesquisa de pós-doutorado que envolve as áreas de Educação não formal e Arte-educação em uma perspectiva intergeracional. $\mathrm{O}$ estudo de teor qualitativo e enfoque fenomenológico baseia-se na metodologia da pesquisa-ação. Envolve gestores, educadores e integrantes do espaço educacional não formal em uma ação participativa. Busca resultados obtidos das experiências vindas da realização de atividades de artes ministradas para crianças, adolescentes e adultas jovens e idosas. Os temas abordados na pesquisa foram: pontos de confluência entre as diversas culturas do adulto, do adolescente e da criança; a percepção e a expressão nas linguagens: gráfica, pictórica e escrita; reconstrução da memória, formação de laços de pertencimento e de vínculos afetivos positivos. A análise dos dados aponta o favorecimento no processo de mudança de atitudes e de desenvolvimento e construção de valores éticos importantes, como: amizade, cooperação e tolerância. Volta-se também à valorização da construção do saber e do conhecimento coletivo em nível local.

Palavras-chave: Educação não formal. Arte-educação e Intergeracional.

\section{Abstract}


This article concerns a postdoctoral research involving non-formal areas of Education and Art education in an intergenerational perspective. The qualitative content of study and phenomenological approach is based on action research methodology. It involves managers, educators and members of non-formal educational space in a participatory action. Search results of coming experiences from performing arts activities taught to children, adolescents and young adults and elderly. The topics covered in the survey were: confluence points among the various cultures of adult, adolescent and child; perception and expression in languages: graphical, pictorial and written; reconstruction of memory, forming bonds of belonging and positive emotional bonds. Data analysis shows favoritism in the process of changing attitudes and the development and construction of important ethical values, such as friendship, cooperation and tolerance. It is also linked to the appreciation of the construction of knowledge and collective knowledge at the local level.

Keywords: Non-formal education. Art education and Intergenerational.

\section{Resumen}

Este artículo se refiere a una investigación postdoctoral involucrando áreas no formales de educación y la educación artística desde una perspectiva intergeneracional. El contenido cualitativo de enfoque de estudio fenomenológico y se basa en la metodología de investigaciónacción. Se trata de directivos, docentes y miembros del espacio educativo no formal en una acción participativa. Resultados de la búsqueda de experiencias próximas que realizan actividades artísticas que se enseñan a los niños, adolescentes y adultos jóvenes y ancianos. Los temas tratados en la encuesta fueron: puntos de confluencia entre las diversas culturas de adultos, adolescentes y niños; la percepción y la expresión en idiomas siguientes: gráfica, pictórica y escrita; reconstrucción de la memoria, formando lazos de pertenencia y vínculos emocionales positivos. Análisis de los datos muestra favoritismo en el proceso de cambiar las actitudes y el desarrollo y la construcción de valores éticos importantes, como la amistad, la cooperación y la tolerancia. Volta es también la apreciación de la construcción del conocimiento y el conocimiento colectivo a nivel local.

Palabras clave: Educación no formal. Arte-educación e Intergeracional.

\section{Introdução}

Educação: Teoria e Prática/ Rio Claro/ Vol. 26, n.52/ p. 212-231/ Mai-Ago. 2016. 
Nos primeiros contatos com o pessoal do PROGEN fui muito bem recebida em um encontro fraternal e promissor. Minha atuação, nesse espaço educacional não formal, diz respeito ao desenvolvimento de um projeto de pós-doutorado baseado em atividades de Arte-educação e fundamentado na iniciativa de oferecer oportunidades para a concretização de vivências intergeracionais. As atividades de artes propostas no projeto foram baseadas no objetivo de integrar dois grupos participantes da entidade, de faixas etárias muito díspares, por meio de uma aproximação afetiva positiva.

Desse modo, o estudo aposta na ampliação do repertório cultural e na melhoria da autoestima dos participantes de idades variadas. Com o suporte de práticas voltadas às potencialidades da arte, está sendo possível criar ambientes integrativos para - diferentes contextos de vidas. Na maioria das oficinas oferecidas, o encontro de gerações se dá por uma espécie de coautoria que ocorre de maneira indireta, pois as produções culturais realizadas circulam entre os dois grupos possibilitando aos participantes a realização de intervenções.

Incontáveis são os encontros e desencontros que acontecem através das diversas convivências e dos resultados dos trabalhos que estão sendo construídos nesse processo de trabalho de pesquisa-ação. Atitudes ligadas a conquistas, renúncias e desejos são configuradas na articulação entre os alcances da pesquisa e os modos de ser da organização.

Algumas parcerias se deram de forma inesperada e foram se gestando a partir da empatia e da credibilidade obtidas no desenvolvimento da pesquisa. Outras tiveram que ser reavaliadas e reformuladas, pois naturalmente surgem adaptações entre o planejamento teórico e a prática.

Quando o assunto se refere às áreas de Educação não formal e de Arte-educação, os ambientes educacionais são privilegiados com processos fluídicos e prazerosos relacionados ao grau de liberdade que se tem para atuar. Como as propostas privilegiam o empenho coletivo e são potencializadas pelos atributos vindos da arte, as atividades acabam se direcionando ao estreitamento de relações.

\section{0 ambiente da pesquisa - um lugar especial}

O PROGEN está localizado no bairro Vila Castelo Branco, na cidade de Campinas, em São Paulo. Segundo Maira Rodrigues (2008), esse bairro foi criado em 1967 a partir da criação de uma COHAB (Conjunto Habitacional). A pesquisadora relata que houve um deslocamento das populações de baixa renda para a periferia da cidade, ocasionada pela valorização imobiliária e sancionada pelo poder público através do desenvolvimento da política habitacional repressora do governo ditatorial dos anos 60-80. Essa segregação espacial influenciou as condições de vida das pessoas, originando muitas perdas. Porém, de acordo com Maira, com a melhoria das condições urbanas, incluindo serviços públicos e privados, as esferas de sociabilidade foram ampliadas. 
O PROGEN surge nesse cenário contribuindo com as redes sociais do bairro, pois sendo uma ONG de cunho educacional e assistencial gerida por membros da sociedade civil, atende aproximadamente 620 pessoas - entre crianças, adolescentes, adultos jovens e idosos, oferecendo 46 oficinas educacionais e de lazer. Dentre essas oficinas algumas são destinadas a atividades esportivas e movimentos corporais, como por exemplo, futebol, capoeira, ginástica olímpica, circo, dança, ioga e Liang Gong ${ }^{1}$. Outras são relacionadas à inserção do público no mercado de trabalho, como a oficina de Informática e Artesanato. Existem ainda atividades culturais e de lazer, além de organizações de marchas pelo bairro comemorando festividades ou manifestando reivindicações. A ONG oferece alimentação incluindo: café da manhã, almoço e lanche da tarde. Também realiza atendimentos psicológicos e encaminhamentos a outros serviços, tais como: posto de saúde, hospitais, conselho tutelar, etc.

As atividades desenvolvidas no PROGEN têm como objetivos principais promover ações articuladas, unificadas e continuadas que contribuam para a inclusão social, prevenção de situações de risco social e transgressão de direitos, buscando propiciar o desenvolvimento integral e o fortalecimento de vínculos afetivos positivos familiares e comunitários. Têm a intenção de garantir espaços de convivência, formação para a participação e cidadania visando à melhoria da qualidade de vida e à ascensão social dos diversos grupos que frequentam a entidade. Também busca com suas ações, garantir aos participantes condições para que usufruam de seus direitos como cidadãos, oferecendo oportunidades para o exercício dessa prerrogativa social e difundindo ampla conscientização sobre a sua importância. Dessa forma, o teor assistencial não reforça um tipo de atuação caritativa, ao invés disso, preconiza o reconhecimento do sujeito de direitos e deveres, apto a autocrítica e a reivindicação de suas prerrogativas enquanto cidadão.

A organização pode criar seus próprios programas e métodos de acordo com as necessidades da comunidade do entorno, porque não é subordinada às políticas educacionais do governo. O público de crianças, adolescentes, adultos jovens e idosos, que atende, tem liberdade para escolher o horário que melhor se adapte à sua rotina diária, sendo que a participação é livre de quaisquer compromissos com a entidade. $\mathrm{O}$ sistema de oficinas educativas, oferecido nesse espaço, facilita o exercício da independência e da autonomia, porque a entidade não indica o que cada participante deve fazer. Além disso, no decurso das atividades todos os componentes são integrados quando suas sugestões, depois de votadas, são estendidas ao grupo, para posteriormente ser postas em prática. São os chamados "combinados", que têm por foco principal o bom funcionamento da organização e o bem estar de seus participantes.

\footnotetext{
${ }^{1}$ Segundo o Manual do Lian Gong da Prefeitura Municipal de Campinas, Lian Gong é uma ginástica desenvolvida na China pelo Dr. Zhuang Yuen Ming, médico ortopedista da Tradicional Medicina Chinesa (TMC), na década de 60 (2015).
} 
Com os grupos de adultos o procedimento se dá com a efetivação de inscrições de livre escolha, sendo que o preenchimento de vagas ocorre respeitando-se a ordem de chegada de acordo com a disponibilidade e a modalidade da oficina.

A grande maioria dessas pessoas tem frequência regular, pois são computados pouquíssimos casos de desistência e isso acontece, justamente, pelos resultados dos benefícios que são oferecidos no âmbito assistencial e educacional responsáveis por transformações visíveis.

\section{0 método e suas potencialidades}

A partir do direcionamento da metodologia da pesquisa-ação, planejo os instrumentos pedagógicos por meio do apoio dos gestores da entidade com o objetivo de construir ações capazes de proporcionar aos agentes da pesquisa, aspectos integrativos, emancipatórios e inclusivos. Os conhecimentos, adquiridos nas oficinas, têm melhores condições de ser fixados e de fazer sentido na vida dos participantes, quando seus diferentes saberes e manifestações culturais são integrados no âmbito da aprendizagem.

Neste caso em especial, outro fator a ser ressaltado relaciona-se à minha consciência de arte-educadora, pois que é necessário estar atenta para seguir relativizando minhas verdades estéticas. Assim é possível receber, sem preconceitos, a multiplicidade de gostos pertencentes a meus educandos. Para o arte-educador é importante que constantemente avalie as ideias que tem sobre o que é arte frente à forte preponderância dos discursos hegemônicos. Deve discernir conceitos elitistas, que muitas vezes foram reforçados em sua formação e acabaram enraizados em suas práticas. É possível ao arte-educador, por meio do contato com outras realidades e com múltiplas apropriações artísticas, desnudar, em suas concepções, valores viciados nos modelos propostos por estruturas de poder conservadoras e excludentes.

Essa autocrítica é benéfica, pois além de reciclar práticas educativas, contribui para o empoderamento do papel social do profissional. Nós arte-educadores "[...] colaboramos para formar a concepção da arte em todos os âmbitos de suas potencialidades para todos os segmentos da sociedade. Sem esquecermos que o conjunto dessas ações consiste em uma parte importante da construção do fazer cultural de um povo" (SIMÃO, 2015, p. 189).

Nilza Alves de Souza explica que, no caso do ensino de arte no Brasil, "melhor pensar a interculturalidade capaz de abarcar a diversidade, numa inter-relação dinâmica, com postura crítica, visando transformar práticas vigentes por meio da participação mais ampla e ativa na cultura socialmente produzida." (2007, p. 66).

Assim, embasada nesse foco intercultural e voltada para a proposta intergeracional, a experiência no PROGEN tem me revelado uma variedade de percursos científicos, práticos, 
imaginativos e inspiradores que ultrapassam as fronteiras da mediação para possibilitar intervenções educacionais mútuas de todos agentes da pesquisa. Como afirma o autor José Carlos Ferrigno, a multiplicidade dos modos de viver nos tempos atuais está facilitando os processos intergeracionais (2006, p. 69).

Por meio da produção e das reflexões originadas na convivência entre os participantes, as capacidades de apreensão, percepção e expressão têm demonstrado sinais de ampliações observadas durante as trocas entre as diferentes culturas. Ewellyne S. de L. Lopes expõe que "o convívio intergeracional possibilitado por programas que estimulam e fortalecem as relações intergeracionais, promove trocas afetivas, oportunidade de crescimento e aprendizado mútuo" (2007, p. 258).

Todas as ações que estão sendo empreendidas na pesquisa são baseadas em iniciativas que buscam se contrapor a instâncias reprodutivistas e antidemocráticas, infelizmente cristalizadas em nossa educação, a meu ver responsáveis pela formação de pseudocidadãos. Digo isto, pois fala-se em demasia sobre a educação para a cidadania, mas, pouco se reflete sobre o que é necessário para formar cidadãos ou sobre quem é esse cidadão. Indivíduos titulares de direitos e deveres civis e políticos frente ao Estado, verdadeiros cidadãos, não deveriam estar intimamente envolvidos com seus contextos geo-político-sociais? Cidadania, segundo Marcos Francisco Martins, "implica a conquista da igualdade, em oposição à sociedade de classes, que promove a divisão social com a negativa de bens e direitos à maioria” (2007, p. 84). Então, será que é possível falar sobre cidadania sem pensar na relação direta com as políticas sociais do país de origem abrangendo ações coletivas, estaduais, regionais ou comunitárias que sejam capazes de ultrapassar interesses pessoais? E ainda, será que são nesses fatores que nós profissionais da educação estamos pensando ao nos esforçarmos para formar cidadãos?

$\mathrm{Na}$ sociedade capitalista, na qual vivemos, é imprescindível contestar as práticas educativas planejadas para qualificar pessoas unicamente induzidas ao acúmulo de capital e à propriedade privada. Em nossos ambientes educacionais é necessário manter preceitos para a difusão de valores políticos, éticos, estéticos e ideológicos, fomentando pesquisas em educação e propostas de intervenção em perspectivas históricas e críticas passíveis de transpor os "muros acadêmicos", atingindo e transformando positivamente parcelas cada vez mais amplas da população. Devemos repudiar práticas educativas etnocentristas, competitivas, meritocráticas, unificadoras e disciplinares, para transmitir conteúdos passíveis de ser construídos de maneira coletiva e heterogênea, problematizando-os. Desse modo será possível propagar a compreensão de que o uso social do conhecimento adquirido é sempre subordinado a algum interesse e que esse interesse, em primeira instância, deve estar voltado ao bem da maioria local, para em seguida continuar atingindo escalas cada vez maiores, investindo na melhoria da qualidade de vida das pessoas em geral. 


\section{Refinamentos da prática - reflexões, surpresas, negociações e trocas preciosas}

As oficinas planejadas para a pesquisa exploram as seguintes linguagens: desenho, pintura, colagem e escrita. Os encontros ocorrem semanalmente, sendo que, atualmente para o grupo de mulheres, eles têm duração de 3 horas. O grupo é composto por 18 adultas com faixa etária variada entre 30 e 78 anos e tem frequência bem assídua. Dentre essas três horas a primeira meia hora é dedicada à realização das rodas de conversa, na qual falamos sobre quase tudo: problemas pessoais, histórias do presente e do passado, política, religião, rotina do espaço e informe de seus acontecimentos especiais. No final faço uma exposição de imagens artísticas, tanto do passado quanto do presente, por meio do datashow, principalmente relacionadas à pintura e ao graffiti, instigando as apreensões, percepções e comentários do grupo.

A conquista por esses espaços de conversas junto às participantes adultas e às crianças e adolescentes começou com a atenção, cuidado e reconhecimento que dediquei às diversas culturas desses diferentes públicos, como: a cultura das crianças, a cultura dos adolescentes, a cultura das adultas jovens, a cultura das adultas idosas. Cada uma dessas culturas é definida por características muito marcantes e é preciso sensibilidade para respeitar sua heterogeneidade. Nessa confluência, a cultura da pesquisadora não fica à margem, e quando falo nela, nesse caso em especial, refiro-me às minhas próprias concepções sobre a arte e sobre a vida. Pude compartilhar essas inserções depois que os sentimentos de empatia e credibilidade ligados ao trabalho desenvolvido já haviam se estabelecido nos ambientes das oficinas.

Atualmente, já é possível acessar outros tipos de conhecimentos com grupos de senhoras utilizando palavras simples em conversas informais. Um assunto interessante, que foi abordado nessas conversas, referiu-se à função social dos projetos desenvolvidos pela arte contemporânea, intensamente ligada à discussão de pontos nevrálgicos da sociedade. Conversamos sobre as relações entre: intolerância e convivência; consumo e exploração; usos e descarte; subversão e reprodução; ecologia e urbanidade; local e global; dominação e mestiçagem, esquecimento e invisibilidade e muitos outros. A maioria das participantes aprecia estas exposições, como nesse exemplo, quando em uma de nossas manhãs eu falava sobre o graffiti e uma senhora comentou:

- É bom voce falar isso prá gente. A gente pensava que isso de graffiti era sujeira.

Mas também existem controvérsias, por exemplo, quando uma delas expressou estranhamento a respeito de uma imagem forte do artista Fernando Botero:

- Prá mim isso é tudo feio. Prá mim isso não é arte!

Para minha satisfação, outra participante contestou o que a colega dizia, explicando que às vezes o bonito parecia feio. 
Para o grupo de crianças, que atualmente apresenta a faixa etária de 9 a 13 anos, o tempo de cada oficina é mais escasso, com uma hora, além de apresentar uma média variada de frequência entre 10 e 17 participantes. O motivo se dá, porque esse grupo pertence às turmas que chegam ao PROGEN após o término do período integral na escola formal. Mesmo com todas as dificuldades de coadunar os tempos com as atividades, essas práticas têm se destacado pelo sucesso que obtém devido aos altos níveis de aceitação e participação obtidos. Ou seja, para esse grupo nossos encontros são sempre uma festa!

Como o PROGEN já atua há 30 anos e as oficinas ocorrem há muito tempo, suas práticas educativas, assim como as concepções sobre seus conteúdos, processos e procedimentos já estavam sedimentados quando cheguei à entidade. Trazer ideias novas é um trabalho muito fino, de minúcias, que requer sensibilidade na escuta, no tratar, e na realização dos planos para introduzir mudanças e transformações de forma gentil e respeitosa. Um exemplo interessante aconteceu logo no início dos trabalhos com o grupo de mulheres, quando eu expliquei que, somente com minha orientação, cada uma iria desenvolver livremente seu próprio processo criativo, escolhendo referências para imagens, cores e técnicas. Uma delas protestou com veemência:

- Eu acho que professora de artes tem que dar um modelo só e todo mundo tem que fazer a mesma coisa. Não concordo em ficar criando coisa prefiro copiar a professora!

Então, principalmente àquelas que se sentiam mais inseguras eu oferecia uma orientação especial, sustentando a proposta de manter cada uma livre para desenvolver seu próprio processo criativo.

Em outro momento, quando eu tentava propor às adultas a confecção de brinquedos pedagógicos para posteriormente serem utilizados pelo grupo de crianças, insatisfeita uma delas exclamou:

- Eu queria mesmo é pintar pano de prato!

Respondi:

- Então vamos pintar panos de prato!

Depois pensei:

"Como vou fazer uma ligação entre os grupos a partir dos panos de prato?"

Percebi que essa era uma oportunidade interessante para testar negociações. Comecei então a ensinar as senhoras a pintar os panos, levando também essa atividade para as crianças e adolescentes com o intuito de presentearem suas mães e avós (Fig. 1). Assim que os integrantes do grupo dos mais novos terminavam seus trabalhos, passei a encaminhá-los para a turma de 
mulheres e, conhecendo suas habilidades, pedi que fizessem um acabamento em crochê em suas barras. As senhoras mais velhas se dispuseram a fazer os rendilhados em crochê com muita animação e, ao receberem os panos, observavam as pinturas das crianças e adolescentes com curiosidade, comentando:

- Quem foi que fez esse aqui?

- Quantos anos ela tem?

- Que graça, olha o que ele escreveu?

Depois retornavam com os panos pintados pelas crianças finalizados com barras de crochê muito coloridas e caprichadas (Fig. 2). Em seguida, eu devolvia os panos de pratos para seus produtores iniciais, isso é, as crianças e os adolescentes. Estes por sua vez, recebiam seus panos de volta com expressões de surpresa e admiração. Era visível como todos se sentiam valorizados nesse intercambio de produções. Crianças, adolescentes e senhoras, todos viram seus trabalhos apreciados em outros recintos por pessoas que não conheciam, mas de certa forma mutuamente muito próximas.

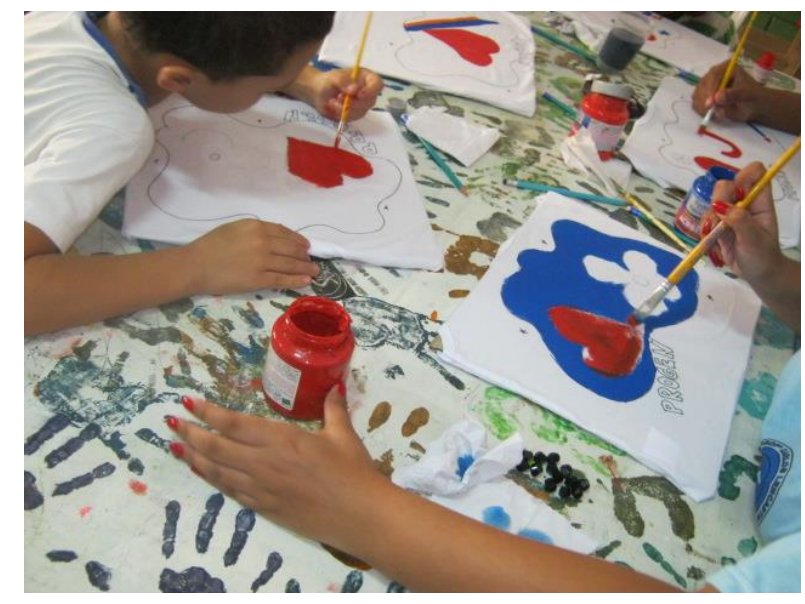

Figura 1: Processo de produção de pintura - Foto da autora.

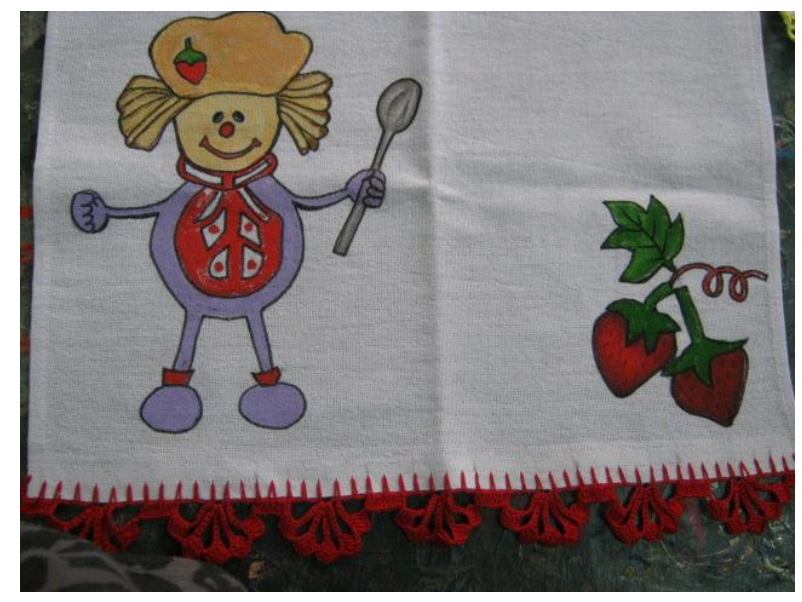

Figura 2: Pano de prato finalizado - Foto da autora.

Essa experiência desencadeou uma série de ideias para as atividades que estariam por vir. Uma delas surgiu quando o grupo de mulheres manifestou o desejo de fazer uma toalha de mesa para ser usada nas festas do PROGEN. Propus que incluíssemos as pinturas das crianças e adolescentes na composição final. $\mathrm{O}$ resultado desses esforços trouxe a finalização de uma grande toalha coletiva pintada pelos dois grupos participantes da pesquisa, de 6 metros de extensão por 3 metros de largura, que atualmente é utilizada nos eventos da organização (Figs. 3 e 4). Os 
desenhos e pinturas foram criados livremente por seus autores, trazendo símbolos e marcas de suas culturas e sendo assinados por eles.
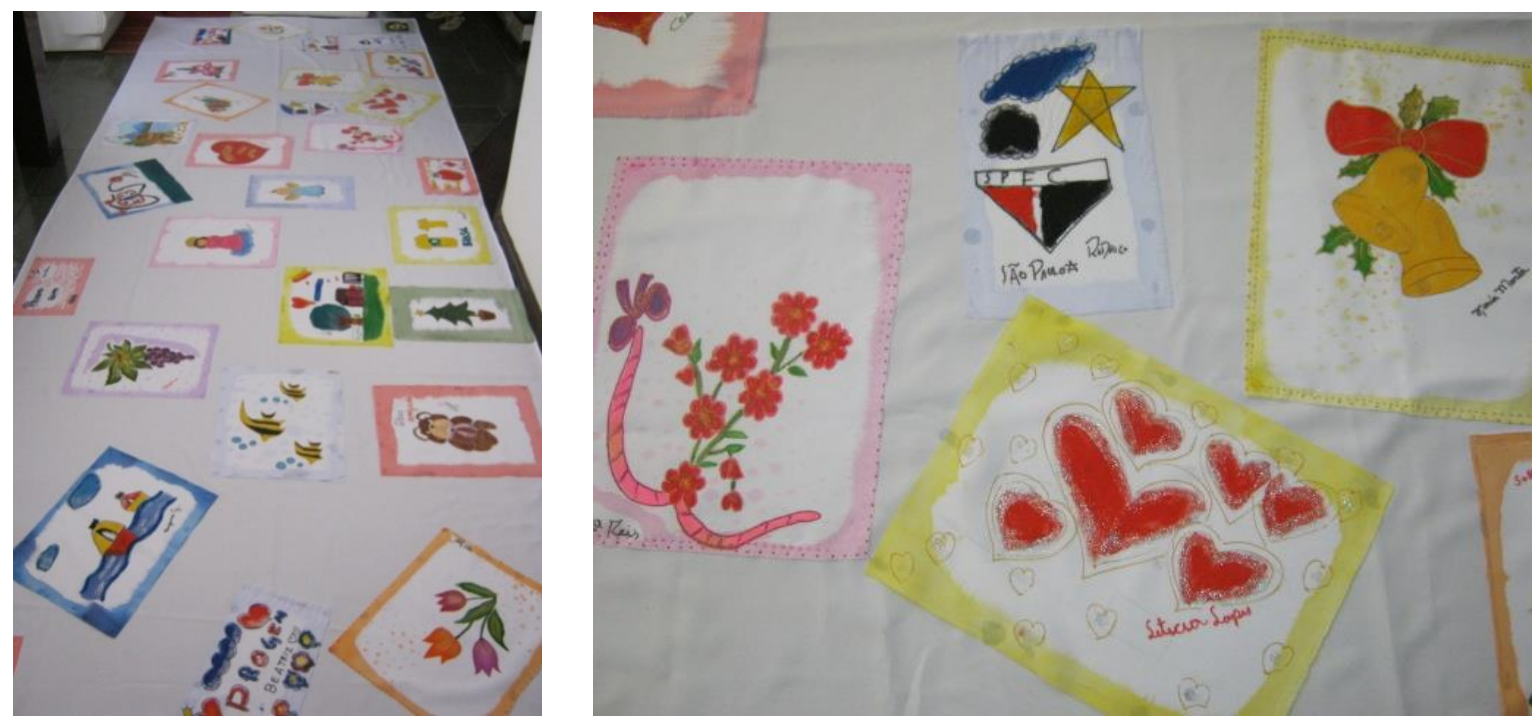

Figura 3: Toalha coletiva finalizada - Foto da autora. Figura 4: Detalhe da toalha - Foto da autora.

Os tempos na entidade compõem um movimento muito dinâmico, sendo que todos estão sempre muito atarefados pelo grande volume de encargos. Assim, para que novas propostas sejam aceitas é preciso idealizá-las responsabilizando-se totalmente pela organização dos espaços e cumprimento pontual dos tempos dedicados a elas. Apesar dessas dificuldades, também encontro parceiros que me ajudam muito no desenrolar dos trabalhos. O exemplo disso se deu com a solidariedade da turma da costura, que atendeu aos nossos apelos e terminou as barras da toalha coletiva.

Outro evento marcante no trabalho de pesquisa, que também envolveu outros segmentos da entidade, foi a exposição de pintura dos trabalhos realizados pelos grupos participantes da pesquisa também aberta à comunidade (Fig. 5). Todos os frequentadores do PROGEN foram convidados a participar e alguns levaram seus familiares para apreciar os trabalhos. 


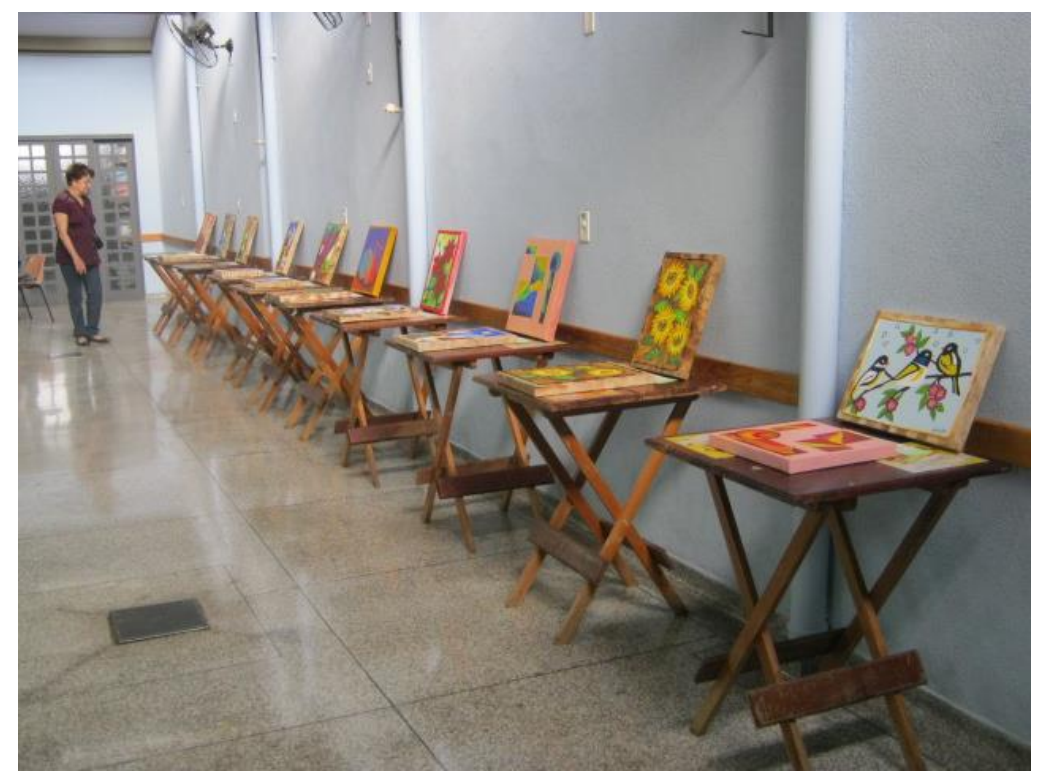

Figura 5: Vernissage dos trabalhos em acrílica sobre tela - Foto da autora.

Ao refletir sobre a atuação do professor de artes, percebo que este tem uma incumbência um pouco mais exigente do que os outros professores em geral, pois podendo usufruir de espaços mais amplos para viabilizar o contato com a subjetividade de seus alunos, possui responsabilidades um tanto sutis, das quais precisa estar atento. Isto porque a arte tem a capacidade de revolver aspectos de autoconhecimento, tanto conscientes quanto inconscientes. Escrevendo sobre seu método, Carl G. Jung, que utilizava arte pictórica para tratar seus pacientes, relatou: “A finalidade desse 'método de expressão' é tornar os conteúdos inconscientes acessíveis e, assim, aproximá-los da compreensão. Com essa terapêutica "consegue-se impedir a perigosa cisão entre a consciência e os processos inconscientes” (1984, p. 120).

Assim, cada gesto, expressão ou fala são sinais importantes do processo criador e se o arte-educador estiver observando essas manifestações, poderá auxiliar no desenvolvimento da produção de seus educandos. Até mesmo expressões de recusa, revolta e frustração podem levar a uma compreensão maior sobre a causa das dificuldades e bloqueios. Cabe ao professor propiciar condições para que seu público possa adentrar em processos de imersão subjetiva de forma suave e criativa, proporcionando ambientes estimulantes, encorajando-os a enfrentar embaraços, oferecendo materiais interessantes, demonstrando técnicas e sugerindo caminhos, mas principalmente apresentando o estado de liberdade e de ousadia que a arte é capaz de provocar.

Nessa perspectiva, não só no processo de criação e na elaboração técnica do objeto artístico que é dada a chance ao estudante de poder desfrutar do autoconhecimento, mas também no ato de expor sua expressão a seus pares. Lidando com diversos sentimentos e percepções, revelando-se a si mesmo e ao outro através de suas produções, o aprendiz também pode vir a 
experienciar outras instâncias, especialmente aquelas que dizem respeito à coragem para se expor, pois fatalmente deverá estar preparado para lidar com diversos tipos de julgamentos, não só os elogiosos, mas também os negativos de rejeição e desaprovação.

Para um professor não é possível prever as manifestações que poderão emergir a partir das experiências que propicia a seus educandos, nem os efeitos dessas revelações perante o grupo. Logo nas primeiras oficinas, presenciei reações um tanto imprevisíveis, pois algumas crianças expressavam, durante as atividades, questionamentos muito íntimos, como neste exemplo de uma menina de 9 anos que me perguntou:

- Sua mãe também te bate?

Outro exemplo se deu também no caso de um menino de 11 anos que, depois de pintar sua camiseta, compartilhou um desejo:

- Vou dar essa camiseta para minha tia que tá presa. Vou escrever meu nome nela prá ela lembrar de mim. Ela tem 18 anos e se meteu com tráfico.

As crianças de 9 a 11 anos encaram as oficinas como um momento de relaxamento no qual podem de imediato criar desenhos, explorar materiais de pintura, inventando maneiras de expressar o que desejam. Os adolescentes a partir dos 12 anos são mais reticentes e demoram um pouco mais para iniciar seus trabalhos refletindo sobre qual seria o melhor tema para desenvolvêlos.

No grupo de mulheres as reações são variadas, principalmente no andamento dos trabalhos de pintura em acrílico sobre tela, pois existem depoimentos afáveis, porém outros nem tanto, como é o caso deste comentário de uma senhora negra pertencente ao grupo das mais idosas e mais antigas participantes na entidade.

- Não estamos aqui para criar? Por que vocês insistem em fazer anjinho loiro de olho azul? Podemos fazer anjos ruivos, negros, japoneses! Saiam do tradicional!

Em outra circunstância, uma senhora desabafou:

- Só minha irmã fazia coisas bonitas. Eu não sabia fazer nada. Eu achava que nunca seria capaz de fazer nada. Isso mudou a minha vida! Agora sou outra pessoa!

$\mathrm{Na}$ ocasião na qual lancei a proposta de pintarem camisetas com imagens dos autorretratos que as crianças e os adolescentes haviam criado em suas oficinas houve certa desconfiança por parte das adultas. Como já tinham experimentado essa trajetória criativa compartilhada com os panos de prato, acabaram aceitando a ideia. Cada uma então escolheu uma imagem pintada em guache dentre os trabalhos que as crianças haviam feito e a reproduziram em uma camiseta (Figs. 6 e 7). Solicitei a cada uma que escrevesse seu nome e sua idade na 
camiseta, além do nome e idade do autor infantil ou adolescente da imagem que havia reproduzido (Fig. 8). As crianças e adolescentes também pintaram autorretratos feitos pelo grupo de mulheres em suas camisetas, seguindo o mesmo processo de forma inversa. Essa atividade trouxe um sentimento de integração interessante, pois as turmas já familiarizadas com a proposta intergeracional, ao vestirem as camisetas propagaram em seus ambientes um clima de cumplicidade, dividindo nesse fazer: a autoria, a vestimenta, os produtos culturais, os materiais, os espaços e a alegria de produzirem juntos.

O grupo de adultas pintou uma série de camisetas para os gestores e funcionários da ONG tendo como temas os desenhos criados pelas crianças. Os trabalhos foram bastante valorizados pelas equipes, e um exemplo disso ocorreu quando o coordenador pedagógico vestiu a camiseta que lhe foi presenteada pelo grupo de senhoras no momento que foi entrevistado por uma estação de TV local, interessada em conhecer o trabalho realizado no PROGEN.
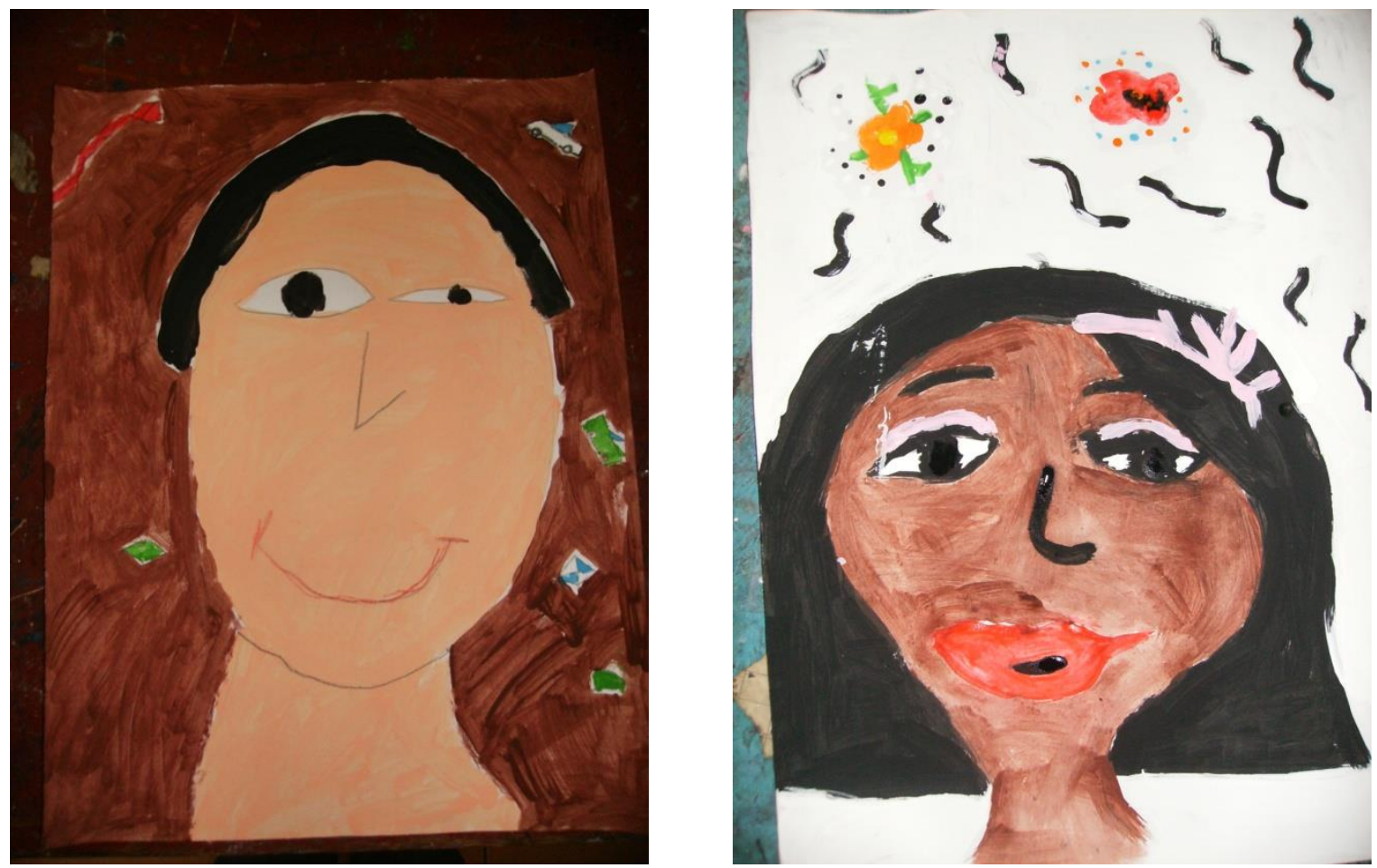

Figura 6: Autorretrato pintado a guache - Foto da autora. Figura 7: Autorretrato pintado a guache - Foto da autora. 


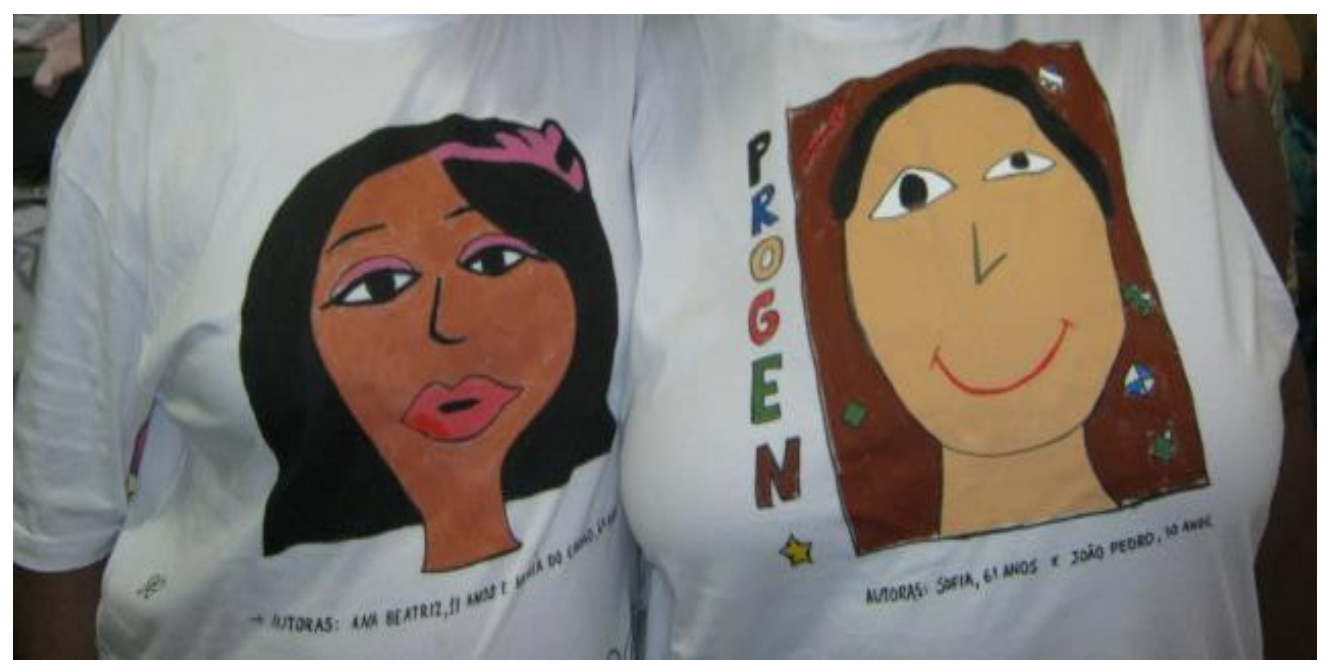

Figura 8: Camisetas pintadas pelo grupo de adultas com imagens dos autorretratos das crianças - Foto da autora.

No PROGEN se exercita uma ação política importante, principalmente nas rodas de conversa, momentos nos quais as vozes da comunidade da comunidade são ouvidas. Em uma dessas rodas de conversa, foram chamadas todas as crianças e adolescentes presentes nesse dia e perguntado por uma educadora o que todos opinavam sobre o significado da palavra cidadania. Isso porque todo o ano a entidade se prepara durante meses para desenvolver um evento com o nome de Ação Cidadã, constituído de apresentações dos trabalhos de quase todas as suas oficinas em uma praça do bairro chamada Praça dos Trabalhadores. Nessa mostra, com a exploração dos espaços externos e divulgação do trabalho realizado, a comunidade acompanha a evolução e as conquistas da organização. Então, nessas conversas durante as rodas, pontua-se como se dá a participação na organização, mencionando-se fatores como: a frequência nas oficinas; o cuidado com os colegas do grupo; a atenção com a ordem e limpeza dos espaços; a autonomia para realização da escolha referente a um modo específico de participação e o direito de sugerir ideias e mudanças. Também são nessas oportunidades que os conflitos são mediados, expondo-se problemas, dificuldades, atitudes equivocadas, etc. Enfim, todos se reúnem efetivando ações voltadas a legitimar transformações positivas para vida cotidiana da entidade por meio da construção de um senso crítico capaz de gerar aspectos voltados à consciência política.

Datas importantes para a concretização desse trabalho não são ignoradas, como o Dia da Mulher, por exemplo. Para essa comemoração, o grupo de mulheres participantes da pesquisa elaborou uma faixa contendo uma frase sugerida por uma delas durante as oficinas: Nós temos orgulho de sermos mulheres. Essa faixa acabou abrindo uma marcha feita pelo PROGEN nas ruas do bairro para comemorar a data (Fig. 9). Nesse dia, mais ou menos 100 pessoas, incluindo crianças, jovens e adultos frequentadores da organização, além de gestores, educadores e funcionários, foram participar da caminhada tocando cornetas, tambores e chocalhos para chamar a atenção dos moradores que surpresos, sorriam e acenavam com entusiasmo. 


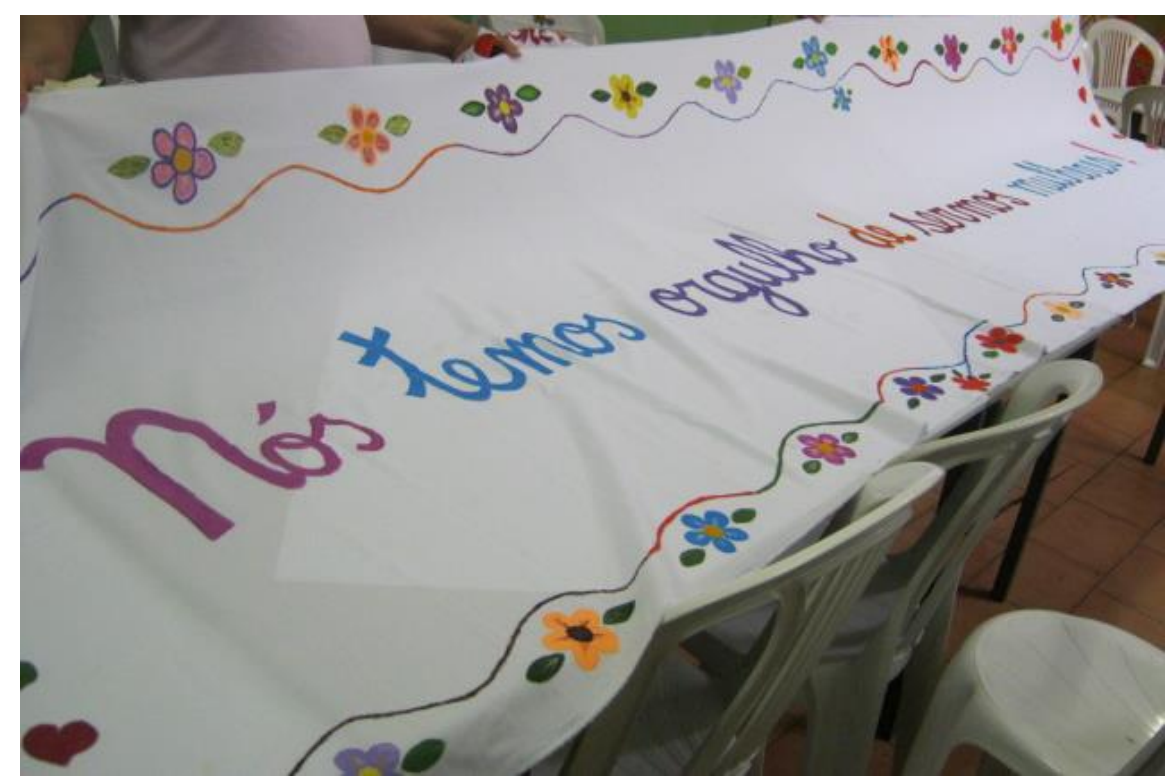

Figura 9: Faixa pintada pelo grupo de senhoras- Foto da autora.

Um dos frutos de todo trabalho da entidade materializou-se na elaboração e publicação de um livro patrocinado pela Petrobras e apoiado pela Fundação FEAC e Prefeitura Municipal de Campinas (Fig. 10). O livro intitulado Mudando a Rotina para Exercer a Cidadania foi publicado em 2015, sendo criado por um ex-frequentador da ONG - Roniel Felipe, jornalista, fotógrafo e escritor. A publicação traz a história do PROGEN, assim como testemunhos de colaboradores, gestores, funcionários e de vários participantes e de seus familiares, contando quais foram os benefícios que receberam em suas vidas a partir do envolvimento com a organização.

Duas páginas desse livro foram dedicadas a relatar um dos feitos importantes da pesquisa: a produção do livro artesanal Contando Histórias. Esse produto cultural que hoje circula pela entidade foi composto coletivamente e traz histórias pessoais escritas pelas adultas jovens e idosas, e ilustradas pelas crianças e adolescentes (Fig. 12). A figura 11 apresenta uma foto presente no livro Mudando a Rotina mostrando uma criança de 10 anos ao lado de uma senhora de 78, ambas segurando o livro Contando Histórias. As duas relatam na página 79, como foi a experiência de integrar suas produções, escrita e pictórica, ou seja, D. Carmem escreveu e Kimberly ilustrou seu texto. Saudosa do companheiro, a aposentada escreveu sobre o dia que conheceu seu marido: 
"Eu o conheci na festa de São Sebastião na cidade de Santo Antônio da Posse. Eu cuidava da barraca do quentão quando ele veio até mim, todo bem vestido, de gravata bordô. Quando chegou bem perto, me perguntou se eu estava só e disse que queria namorar comigo. Eu disse que queria casar", recorda.

Coube à pequena Kimberly desenhar a história de amor, que acabou em um casamento que durou 55 anos e rendeu quatro filhos. "Eu achei muito interessante o que li. Ele realmente estava apaixonado por ela, pois insistiu até conquistá-la [...]" (FELIPE, p. 79-80, 2015)

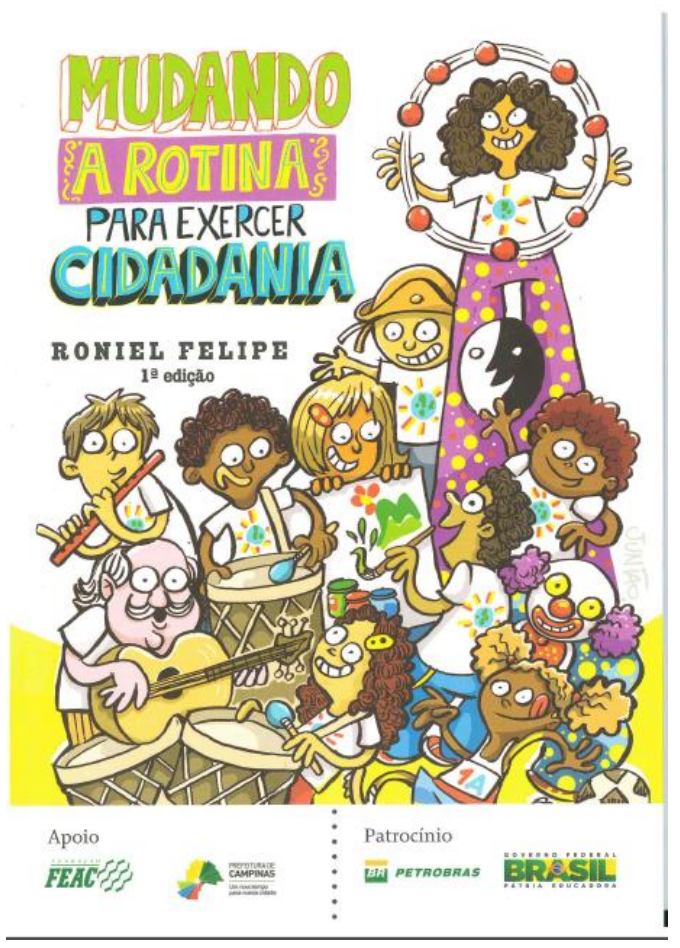

Figura 10: Imagem escaneada pela autora da Capa do livro Mudando a Rotina. 


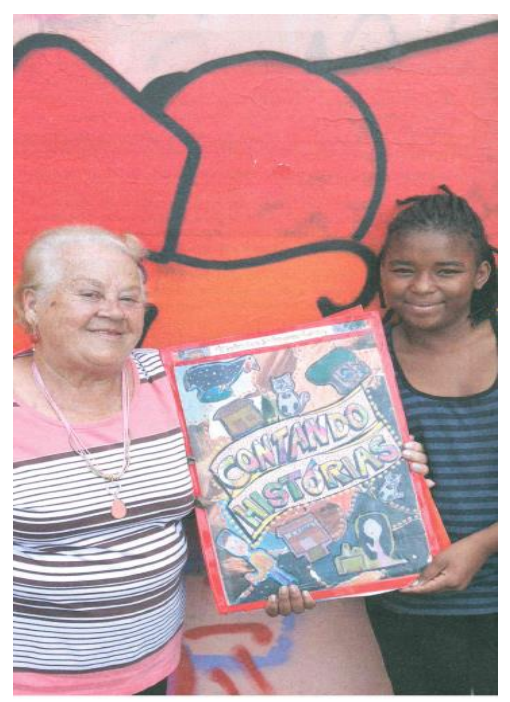

Figura 11: Imagem escaneada pela autora da foto da página 78 do livro Mudando a Rotina.

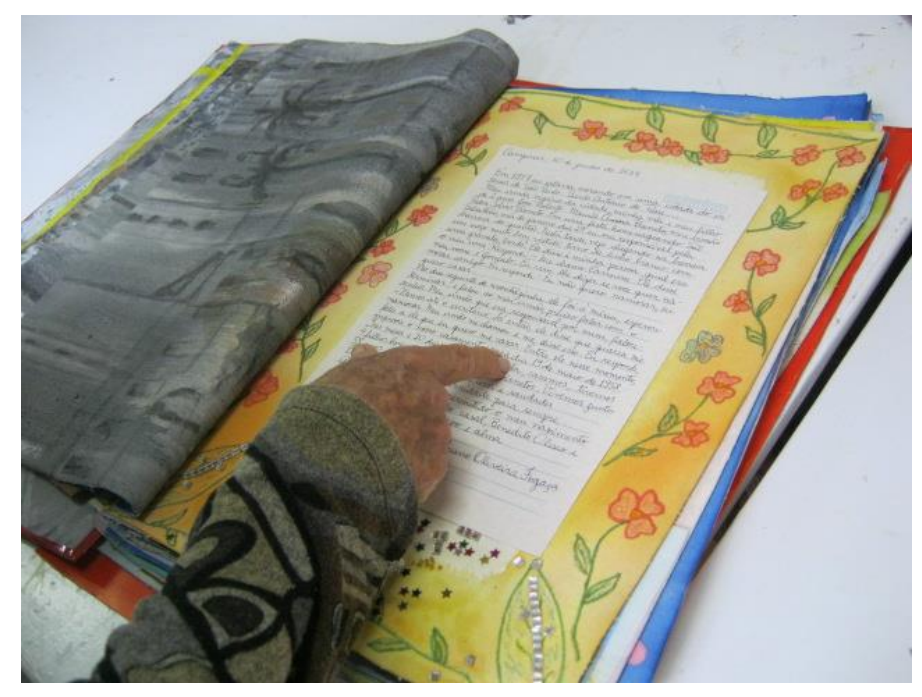

Figura 12: Livro artesanal: Contando histórias - Foto da autora.

Desde o começo da pesquisa, 1 ano e 8 meses após o seu início, verifiquei a materialização de um aspecto positivo de integração entre as pessoas resultante da minha atuação influenciando a proposta pedagógica da entidade. Essa constatação se deu a partir da descoberta de que as instruções atuais, que estão sendo dadas aos coordenadores pelos gestores da organização, estão dirigidas a orientá-los para que as atividades planejadas pelas equipes de educadores tenham mais ênfase na proposta intergeracional. Ou seja, uma transformação visível 
relacionada ao aprofundamento da conscientização da necessidade de integrar diferentes faixas etárias nos processos socioeducativos da entidade.

\section{Considerações Finais}

O PROGEN é um espaço privilegiado para uma pesquisa científica, pois fomenta a compreensão dos direitos e deveres de cidadãos participantes envolvidos com as questões que dizem respeito à vida social, familiar e profissional. Muitas vezes as organizações de educação não-formal são tidas como lugares dedicados somente ao entretenimento e lazer das populações do entorno. Objetivos que se constituem somente de uma pequena parte da intencionalidade do campo da educação não formal, pois, de modo óbvio, essa modalidade educativa, que traz em seu bojo a palavra "educação", deve perseverar em cumprir completamente seus desígnios. As entidades não formais em geral, que se intitulam organizações educacionais, deveriam fazer jus a esses objetivos com seriedade, como o faz o PROGEN, além de lutar para melhorar seu atendimento a partir de suas conquistas.

Inserida nesse ambiente profícuo ao contexto educativo, a pesquisa está obtendo resultados concretos na busca da integração entre diferentes faixas etárias que ocupam os mesmos espaços sem se encontrarem fisicamente, pois isso ocorre somente em ocasiões especiais. As interfaces geradas pelas produções em cumplicidade de crianças, adolescentes, adultas jovens e idosas trouxeram um caráter de oposição às formas de hierarquização, competição e enrijecimento pedagógico que permeiam os ambientes educativos. A proposta está sendo capaz de cultivar valores de respeito entre as pessoas apesar de suas divergências, ao exercerem práticas voltadas à solidariedade, ao bem coletivo, ao respeito à família e às diversidades.

Porém, como sabemos, onde há relações humanas inevitavelmente também existem disputas, sentimentos de aversão a mudanças, intransigências, etc. Quando esses descompassos surgem nos trabalhos referentes à pesquisa, são enfrentados como oportunidades ímpares para o aprendizado que se relaciona ao convívio e à abertura. É no encontro com o outro que reconhecemos nossos limites, fraquezas e idiossincrasias, assim como também, são nessas ocasiões que surgem concepções capazes de nos tirar dos vícios da intolerância e da estagnação. Por isso a necessidade de criar e apoiar espaços e iniciativas educacionais voltados ao diálogo aberto, franco e construtivo.

Sendo o PROGEN uma entidade sem fins lucrativos, engajada na luta para que os direitos básicos da criança, do adolescente e do adulto jovem e idoso sejam oferecidos sem distinção, tem o perfil adequado a esse propósito libertário. Como um espaço de educação não formal, que acredita nas ações voltadas à criação de uma sociedade igualitária, repudia formas socioeducativas exclusoras e antidemocráticas. 
Obviamente, o PROGEN esforça-se constantemente para superar as dificuldades, principalmente ligadas à captação de verbas e parcerias e preenchimento de lacunas referentes à formação dos educadores. Contudo, constitui-se em uma organização apropriada aos objetivos de profissionais da Educação movidos pelo desejo de contribuir para o "fortalecimento da educação pública, laica, participativa, inclusiva, gratuita e de qualidade socialmente referenciada", dizeres da $25^{\mathrm{a}}$ Nota Pública do Fórum Nacional de Educação - Conjuntura politicoeducacional, publicada em 25 de março 2015, decorrente do discurso governamentista baseado no lema "Brasil Pátria Educadora".

Intenções que vão de encontro a políticas públicas educacionais que continuam a se enveredar em desvios guiados pelo axioma do pensamento liberal, tecnicista, seletivo e individualista. Caminhos já percorridos e intensamente corroídos por resultados desastrosos, responsáveis pelo caráter desigual da Educação brasileira e pela precarização do ensino público. São políticas que se firmam como mais interessadas na criação de instituições paralelas, identificadas com a classe empresarial e com institutos privados.

Para que possamos construir democraticamente em nosso país uma "Pátria Educadora" é necessário instrumentalizar instituições de ensino públicas, formais e não formais interdisciplinarmente, unindo saberes da Pedagogia, da Psicologia e do Serviço Social, além de oferecer melhores condições de trabalho aos profissionais envolvidos.

Com um olhar mais amplo que se esforce em atender todas as dimensões da formação do ser humano, urge que de uma vez por todas, sejamos capazes de respeitar a diversidade cultural e os contextos históricos das comunidades locais, valorizando os acontecimentos significativos das vidas das pessoas. $\mathrm{O}$ ato de consagrar as diversas formas culturais e sabedorias populares, incorporando-as nas esferas educativas cotidianas, possibilitará que os conhecimentos historicamente acumulados possam ser disseminados em formas de acesso diversificadas e motivadoras. Os elementos extraídos dos saberes locais poderão ser ressignificados e enriquecidos, identificando-se suas múltiplas conexões com os aspectos universais do campo científico em ambientes estimulantes para o desenvolvimento de interesses e potencialidades.

\section{Referências}

FELIPE, D. J. Mudando a rotina para exercer a cidadania. Campinas: Apoio Fundação FEAC, Prefeitura de Campinas. Patrocínio PETROBRÁS. : 2015.

FERRIGNO, J. C. A co-educação entre gerações. Rev. bras. Educ. Fís. Esp., São Paulo, v.20, p.67-69, set. 2006.

JUNG, C. G. Memória, sonhos e reflexões. Rio de Janeiro: Nova Fronteira, 1984. 361 p. 
LOPES , E.S. de L. Palavras-chave em Educação não-formal. In: PARK, M. B.; FERNANDES, R. S. e CARNICEL, Amarildo. (Orgs.) Relações Intergeracionais. Holambra, SP; Editora Setembro: Campinas SP: CMU, 2007. p. 257-258

PREFEITURA MUNICIPAL DE CAMPINAS. Manual do Lian Gong. Disponível em: <www.campinas.sp.gov.br/arquivos/.../manual_lian_gong_01.pdf>. Acesso em: 15, mar. 2015.

MARTINS, M. F. Palavras-chave em Educação não-formal. In: PARK, Margareth B.; FERNANDES, R. S. e CARNICEL, A. (Orgs.) Cidadania. Holambra, SP; Editora Setembro: Campinas SP: CMU, 2007. p. 83-84

RODRIGUES, M. Mudanças na segregação espacial em Campinas e influência sobre as redes sociais de pobres urbanos. 2009. 116 páginas. Dissertação de Mestrado. Universidade de São Paulo - Faculdade de Filosofia, Letras e Ciências Humanas - Departamento de Ciência Política. São Paulo, 2008.

SIMÃO, S. M. Eu, meu bairro, nosso mundo. Educação não formal: saberes e prazeres. Holambra, SP: Editora Setembro, 2014. 384 p.

SOUZA, N. A. de. In Palavras-chave em Educação não-formal. PARK, M. B.; FERNANDES, R. S. e CARNICEL, A. (Orgs.) Arte-Educação. Holambra, SP: Editora Setembro: Campinas SP: CMU, 2007. p. 65-66

25a Nota Pública do Fórum Nacional de Educação - Conjuntura político-educacional. Disponível em: < http://contee.org.br/contee/index.php/2015/03/25a-nota-publica-do-forumnacional-de-educacao-conjuntura-politico-educacional/>. Acesso em: 25, mar. 2015.

Recebido em: 08/06/2015

Aprovado para publicação em: 12/05/2016

Publicado em: 31/08/2016 